\title{
Anatomical Considerations: The Relationship Between The Vertebral Artery And Transverse Foramina At Cervical Vertebrae 1 To 6 In Patients With Vertigo
}

\author{
${ }^{1}$ Turgut Kültür MD, ${ }^{2}$ Nuray Bayar Muluk MD, ${ }^{3}$ Cihan lyem PhD, \\ ${ }^{4}$ Mikail Inal MD, ${ }^{5}$ Veysel Burulday MD, ${ }^{6}$ Murat Alpua MD, ${ }^{7}$ Umut Orkun Çelebi MD, \\ 1 Doctor Faculty Member at Kırlkkale University, Faculty of Medicine, Dept. of Physical Medicine and Rehabilitation, Kırlkkale, Turkey \\ 2 Professor at Kırlkkale University, Faculty of Medicine, ENT Department, Kırlkkale, Turkey \\ 3 Doctor Faculty Member at Kirlkkale University, Faculty of Medicine, Department of Anatomy, Kırlkkale, Turkey \\ 4 Associate professor at Kırlkkale University, Faculty of Medicine, Radiology Department, Kırıkkale, Turkey \\ 5 Associate professor at Kirlkkale University, Faculty of Medicine, Radiology Department, Kırlkkale, Turkey \\ 6 Doctor Faculty Member at Kırlkkale University, Faculty of Medicine, Neurology Department, Kırlkkale, Turkey \\ 7 Specialist at Kırıkale University, Faculty of Medicine, Radiology Department, Kırıkkale, Turkey
}

\begin{abstract}
Objective: In this study, we aimed to investigate the relationship between the size of the vertebral artery and that of the transverse foramina at the $\mathrm{C} 1$ to $\mathrm{C} 6$ vertebral level in patients suffering from vertigo thought to be related to vertebrobasilar insufficiency (VBI).
\end{abstract}

Materials and Methods: In this retrospective study, two groups were compared in terms of cervical computed tomography (CT): 22 adult patients with vertigo; and a control group consisting of 23 healthy adult individuals. Measurement of the vertebral artery and transverse foramina (i.e. sagittal and transverse dimensions, plus area) were performed bilaterally at levels C (cervical vertebra) 1 to $\mathrm{C} 6$.

Results: For the cases group, at C6 level the right vertebral artery area, sagittal and transverse diameter were larger than in the control group at the level of statistical significance. At C1 level, the area of the right transverse foramina in the cases group was significantly higher than in the control group. At levels $\mathrm{C} 1$ to $\mathrm{C} 5$, the values ob- tained for vertebral artery area were positively correlated with the values for the ipsilateral transverse foramina (transverse foramen sagittal and transverse dimensions plus areas). Where the sagittal or transverse dimensions of the transverse foramina, or the area of the transverse foramina were found to be decreased, vertebral artery areas were also observed to have decreased at C1 to C5 levels.

Conclusion: We concluded that a decrease in diameter of the bony structures or transverse foramina may cause a decrease in the cross-sectional area of the vertebral artery on the ipsilateral side. Since it is only the left vertebral artery which is dominant for cerebral blood flow, any compensatory increase in right vertebral artery area cannot offset decreased cerebral blood flow. Decreased blood flow (i.e. VBI) on the left side may play a role in the development of vertigo.

Keywords: Vertebral artery, transverse foramina, vertigo, vertebrobasilar insufficiency, multi-slice computed tomography.
Correspondence: Dr. Turgut Kültür

Kırıkkale University, Faculty of Medicine, Department of Physical Medicine and Rehabilitation, Kırıkkale, Turkey e-mail: kurgut@hotmail.com

Received: 30th, November, 2018; Accepted: 10th, December, 2018
Online available at: www.entupdates.org

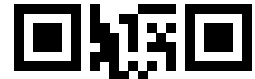

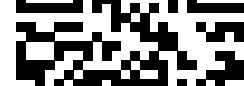

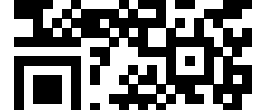




\section{Introduction}

Temporary ischaemic blockage of the vertebrobasilar vessels is termed vertebrobasilar insufficiency (VBI)[1]. Feeling dizzy on one occasion or more is seen in above $60 \%$ of cases where VBI is diagnosed [2]. Typically, this haemodynamic alteration causing VBI is secondary to atherosclerotic disease, but is also frequently due to emboli, atherosclerotic disease of the great vessels or a dissecting artery. Somewhat rarer reasons include migraines, fibromuscular dysplasia, clotting disorders or substance misuse [3]. If a patient has both vestibular symptoms and is at risk of ischaemic heart disease, a diagnosis of VBI needs to be considered $[4,5]$.

The vascular supply to the pons, medulla, cerebellum, mesencephalon, thalamus, occipital lobe and the central and peripheral vestibular apparatus is via the vertebral artery and basilar artery $[6,7]$. Any interruption to this supply may lead to nausea, lightheadedness, fainting, difficulty swallowing, speech problems, balance disturbance and hearing and seeing problems [8-10]. Where these key CNS regions are under-perfused, symptoms may begin abruptly, with a variable time course and incidence and may occur singly or as a cluster of related symptoms [11-13].

Medical imaging is a modality that can be used to assess and evaluate the sufficiency or otherwise of the vertebrobasilar circulation. Stenotic lesions of the carotids may be diagnosed ultrasonographically [14]. Magnetic resonance angiography (MRA) has achieved enviable rates of accuracy and specificity in diagnosing lesions of the distal portions of the vertebral arterial tree $[13,15]$. For this research, an investigation of the vertebral arterial dimensions and those of the transverse foramina at levels C1 to C6 in cases of known vertigo was undertaken. Each such case was suspected to represent VBI. The measurements were taken from cervical CT scans.

\section{Materials and Methods}

This was a retrospective study, undertaken at Kurıkkale University Faculty of Medicine and in accordance with the principles of the Declaration of Helsinki. CT images were accessed from the database of the Kırıkkale University Faculty of Medicine Radiology Department. Ethics Committee Approval from Kırıkkale University Clinical Researches Ethics Committee was also obtained (Date: 01/06/2015 Number: 14/07).

\section{Subjects}

A retrospective methodology was employed. The hospital PACS system was queried for cases investigated for vertigo, including most recently. Scans for 22 adults $(13$ men and 9 women) were located. The subgroup with vertigo was chosen from within suspected cases of VBI. In each case, turning the neck brought on vertigo, with an otherwise normal nervous system examination. The mean age cases in the vertigo group (Group 1) was 56.5 \pm 11.6 (range: 2975) years.

The control group consisted of cervical CT images from 23 healthy adults (11 males and 12 females), found from the hospital's PACS database, which was queried for suitable records done at any time up to very recently. The mean age for individuals in the control group (Group 2) was $54.0 \pm 15.8$ years (range: $23-76$ ).

Cases with a history of trauma or surgical intervention to the neck, skull, ear or cervical vertebrae with fusion defects were not included, nor were individuals with hypoplasia of the vertebral artery, or a diagnosis of other peripheral and central causes of vertigo, e.g. Benign Paroxysmal Positional Vertigo (BPPV) or vestibular neuritis.

\section{Computed Tomography Measurements}

The scans were all produced by routine procedures for cervical $C T$ and were in the supine position. Scans were without contrast and patients were unsedated. A 64-slice CT (MSCT; Brilliance 64, Philips Medical System, Best, the Netherlands) was used for image acquisition. The settings employed in each case were as follows: tube voltage $=120$ $\mathrm{kV}$, effective $\mathrm{mAs}=300$, slice thickness $=1.00 \mathrm{~mm}$, field of view $(F O V)=200 \mathrm{~mm}$, and image matrix $=512 \times 512$. After image transfer to a standard workstation, bone algorithms were used in reconstruction of the raw data. Following scanning, slices $1.00 \mathrm{~mm}$ thick were reconstructed in the coronal, axial, and sagittal planes. Two radiologists were each responsible for performing all the necessary measurements, and the values used for analysis were taken as the arithmetic mean of each measurement as performed by the two observers.

For both the case and control groups, vertebral artery and transverse foramina measurements (Sagittal and transverse dimensions; and area) (Figure 1) were measured bilaterally (right and left) at the levels of the $\mathrm{C} 1$ to C6 vertebrae. The measurements covered: 

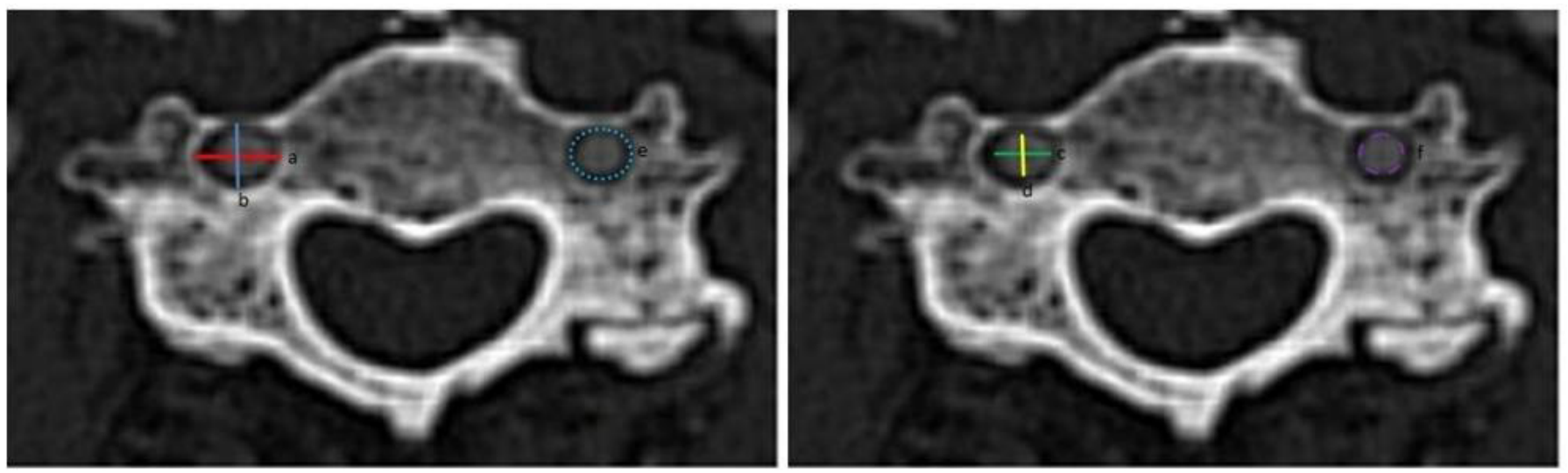

Figure 1. Vertebral artery and transverse foramina measurements. a) Transverse diameter of the transverse foramina, b) Anteroposterior diameter of the transverse foramina, c) Transverse diameter of the vertebral artery, d) Anteroposterior diameter of the vertebral artery, e) Area measurement of the transverse foramina f) Area measurement of the vertebral artery.

1.Vertebral artery sagittal diameter (VASD): The width of the anterior-posterior aspect of the vertebral artery in the transverse foramen in those transverse sections where it is most clearly visible.

2. Vertebral artery transverse diameter (VATD): The width of the right-left aspect of the vertebral artery in the transverse foramen in those transverse sections where it is most clearly visible.

3. Area of the vertebral artery (VAA): The area of the vertebral artery in the transverse foramen in those transverse sections where it is most clearly visible.

4. Transverse foramina sagittal diameter (TFSD): The width of the anterior-posterior aspect of the transverse foramina in those transverse sections where it is most clearly visible.

5. Transverse foramina transverse diameter (TFTD): The width of the right-left aspect of the transverse foramina in those transverse sections where it is most clearly visible.

6. Area of the transverse foramina (TFA): The area of the transverse foramina in those transverse sections where it is most clearly visible

\section{Statistical Analysis}

The SPSS for Windows 16.0 application (SPSS, INC, an IBM Company, Chicago, Illinois) was used for all statisti- cal analyses. The Mann Whitney U Test, Wilcoxon signed ranks test and Spearman's Correlation Rho Efficient Tests were employed for comparisons.

A cut-off value of $\mathrm{p}<0.05$ was taken to indicate statistical significance.

\section{Results}

The sagittal and transverse diameters of the vertebral artery are listed in Table 1 . At the C6 level (right side) both $\operatorname{VASD}(\mathrm{p}=0.015)$ and VATD $(\mathrm{p}=0.043)$ of the vertigo group were raised in comparison with the control group at the level of statistical significance. In both vertigo and control groups, the VASD and VATD values did not differ significantly between right and left side (see Table 1).

Area values obtained for the vertebral artery (VAA) are listed in Table 2. At C6 level (Right side), the VAA values in the vertigo group showed a statistically significant increase compared to those of the control group ( $\mathrm{p}=0.017)$. In the control group, the left VAA values showed a statistically significant increase compared to the right side at levels $\mathrm{C} 4$, C5 and C6 (see Table 2).

The sagittal and transverse diameters of the transverse foramina are listed in Table 3. The TFSD and TFTD values of vertigo and the control groups $(p>0.05)$ exhibited no statistically significant differences. In Group 2, at C6 level, TFTD on the left side was raised at a significant level compared to the right side $(\mathrm{p}=0.017)$ (Table 3$)$.

The area of the transverse foramina is given in Table 4. At C1 level, the vertigo group had values for the right TFA that were higher than in the control group $(\mathrm{p}=0.007)$, 
at the level of statistical significance. At $\mathrm{C} 1$ level, the values obtained for the left TFA, and at the C6 level, those obtained for the right in individuals in the control group, when compared with the contralateral side, were found to be significantly elevated $(\mathrm{p}<0.05)$ (Table 4$)$.

\section{Spearman's correlation rho efficient test results}

Spearman's correlation rho efficient test was used to evaluate the relationship between VAA and transverse foramen sagittal and transverse dimensions, plus the area values at C1 to C6 levels. With the exception of the C6 level, each of the right and left side VAA values were positively correlated with the values obtained for the ipsilateral transverse foramina (transverse foramen sagittal and transverse dimensions, and areas) at $\mathrm{C} 1$ to $\mathrm{C} 5$ levels. The dimensions of the Transverse foramina in the sagittal or transverse plane, together with the area of the transverse foramina were found to decrease to the same extent as the vertebral artery area (see Table 5).

\section{Discussion}

VBI is a form of transient ischaemic attack (TIA) produced by temporary blockage of the vertebral artery and hence posterior circulation, itself brought about by turning the head or extending the neck [16]. It is a haemodynamic problem related to rotation and secondary to degeneration within the cervical vertebrae [17] or manipulation of the neck area $[18,19]$. The sensations of vertigo that accompany certain actions of the head or cervical region may, however, be brought about through vestibular malfunction or originate in the neck itself. Since VBI is the most serious of the differential diagnoses to consider, it needs to be excluded first [13]. The clinical presentation of VBI is with vertigo, double vision, dysarthric speech, dizziness (symptoms that originate in the brain stem) and impaired vision (arising from occipital cortical involvement) [4,20].

The present research assesses the relationship between the dimensions of the vertebral artery and the transverse foramina of the $\mathrm{C} 1$ to $\mathrm{C} 6$ vertebrae in patients with vertigo. At the C6 level, the area of the right vertebral artery, sagittal and transverse diameter in the vertigo group was significantly larger than in controls. At the level of C1 level, this relationship held for the area of the right transverse foramina. In $70 \%$ of individuals, the left vertebral artery is dominant for cerebral blood flow. There is an increased velocity of blood flow and raised volume on the dominant side [21]. In the control group, the left vertebral artery area values were larger than those for the right side at $\mathrm{C} 4, \mathrm{C} 5$ and C6 levels, at the level of statistical significance. Enlargement of the left vertebral artery may ensure an enhanced vascular supply to the brain, thus avoiding the onset of vertigo symptoms.

In the present study, the values for vertebral artery area were positively correlated with the values for the ipsilateral transverse foramina (transverse foramen sagittal and transverse dimensions, plus areas) at $\mathrm{C} 1$ to $\mathrm{C} 5$ levels. When the transverse foramina sagittal or transverse dimensions, or area of the transverse foramina decreased, vertebral artery areas also decreased at $\mathrm{C} 1$ to $\mathrm{C} 5$ levels. We concluded that a decrease in the diameter of bony structures or the transverse foramen may cause the vertebral artery on the ipsilateral side to be smaller. The diameter of the vertebral artery may be contributing to vertigo development by affecting blood flow via a decrement in the area of the artery. It is this diminution in blood flow that plays a vital role in the development of vertigo, in other words, VBI.

Cote et al.[22] Employed the extension rotation screening test to observe what happened to flow within the vertebral artery. For individuals whose necks were both rotated and extended simultaneously, doppler vascular studies failed to show any diminution in flow, despite the individual experiencing the full symptoms of VBI [22]. These apparently false negative findings may be due to the vertebral artery still remaining patent and the collateral circulation increasing whilst tests to screen for VBI are being performed [23].

Incomplete occlusion of the vertebral artery whilst undergoing screening will entail no cessation of vascular perfusion of the cortex. There may be an adequate collateral arterial supply from large bore vessels, such as the internal/external carotids, or smaller vessels (anterior/posterior communicating arteries) to counteract the effect of attempts to provoke the phenomenon in screening. This is so much the case, that some researchers consider VBI screening to be, in effect, a test of collateral circulation in an individual with insufficient vertebral arterial supply [13, 24].

Bow Hunter syndrome is used to describe the way the vertebral artery is blocked by turning the head. In this syndrome, vertebrobasilar insufficiency is due to proximal arterial blockage near $\mathrm{C} 7$ in $4 \%$, between $\mathrm{C} 3$ and $\mathrm{C} 7$ in $58 \%$, between $\mathrm{C} 1$ and $\mathrm{C} 2$ in $36 \%$ and distally to $\mathrm{C} 1$ in $2 \%$ of sufferers. These are termed segments V1-V4, respectively [25]. 
Table 1: Sagittal and transverse dimensions of the vertebral artery

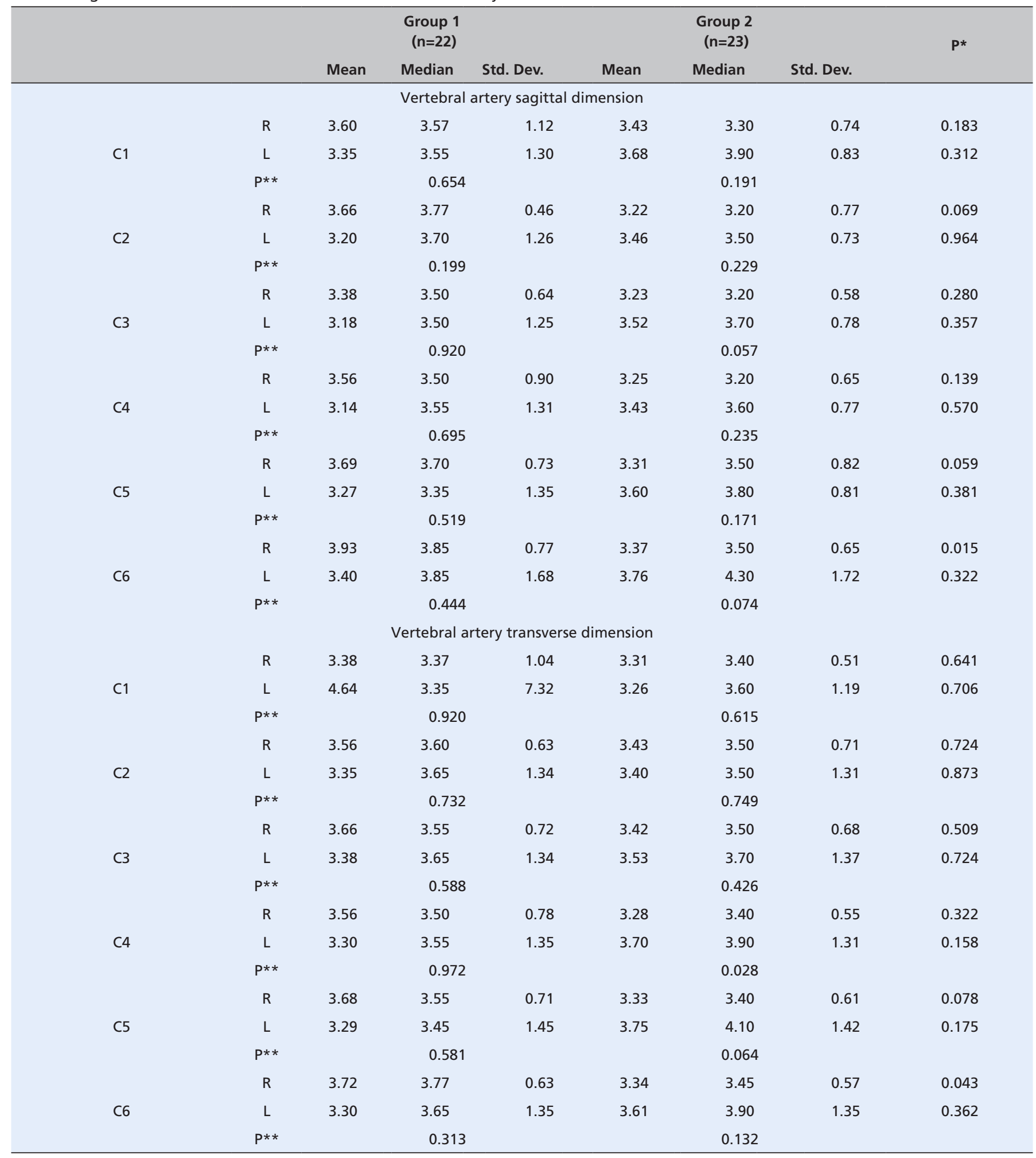

* $p$ value shown for the results of Mann Whitney $U$ test

**p value shown for the results of Wilcoxon signed ranks test 
In the present study, the increased size of the right vertebral artery may arise due to a compensatory mechanism balancing reduced left flow. One limitation in our results is that arterial flow was not measured. For the vertigo cases, the symptoms had been produced by turning the head, but the CT scans were not obtained in this position.

Akar et al. [26] performed a cadaveric analysis of the branches of the vertebral artery within the skull in 11 cases. The left vertebral artery was larger in two individuals, the right larger in five individuals, and both the same size in four individuals. The vertebral arteries for each side were joined at four levels of the pontomedullary junction at the level of the basilar arteries, $2 \mathrm{~mm}$ lower in one individual, but for six individuals, 1 to $7 \mathrm{~mm}$ higher.

Gordhan and Lockhart [27] suggest that congenital anomalies of the cervical transverse foramina may be present bilaterally in instances of VBI or infarction occurring in adults. In the present study, there was a positive correlation between the area of the vertebral artery and the area and diameter of the transverse foramina. The decrease in the transverse foramina was associated with a decrease in the value for the area of the vertebral artery.

For the majority of the population, the left vertebral artery is dominant for cerebral blood flow, therefore any increase in the right vertebral artery area cannot materially affect cerebral blood flow. We conclude that a decrease in the left vertebral artery area may produce a diminution in cerebral blood flow and hence cause vertigo. In addition, the change in blood flow rate in VBI may contribute to the development of atherosclerotic changes by inducing turbulence. We plan to perform a further study including doppler ultrasonography to evaluate blood flow in the vertebral arteries. For this future study, measurements will be taken for both the normal anatomical position and with the head rotated. This should allow discussion of the relationship between decreased vertebral arterial area and transverse foramina, and blood flow rates within the vertebral arteries.

Table 2: Area of the vertebral artery

\begin{tabular}{|c|c|c|c|c|c|c|c|c|}
\hline & & \multicolumn{3}{|c|}{$\begin{array}{c}\text { Group } 1 \\
(n=22)\end{array}$} & \multicolumn{3}{|c|}{$\begin{array}{c}\text { Group } 2 \\
(n=23)\end{array}$} & \multirow[t]{2}{*}{$P^{*}$} \\
\hline & & Mean & Median & Std. Dev. & Mean & Median & Std. Dev. & \\
\hline & $\mathrm{R}$ & 11.45 & 11.80 & 5.55 & 9.826 & 9.80 & 4.12 & 0.266 \\
\hline \multirow[t]{3}{*}{ C1 } & L & 10.79 & 11.70 & 5.13 & 12.29 & 12.20 & 5.29 & 0.260 \\
\hline & $\mathrm{P} * *$ & & 0.741 & & & 0.066 & & \\
\hline & $\mathrm{R}$ & 11.27 & 12.35 & 2.94 & 9.69 & 10.30 & 3.44 & 0.102 \\
\hline \multirow[t]{3}{*}{ C2 } & L & 10.77 & 12.00 & 5.77 & 11.34 & 12.50 & 6.33 & 0.690 \\
\hline & $\mathrm{P} * *$ & & 0.709 & & & 0.254 & & \\
\hline & $\mathrm{R}$ & 14.57 & 9.95 & 19.98 & 9.53 & 10.10 & 3.41 & 0.370 \\
\hline \multirow[t]{3}{*}{ C3 } & L & 9.79 & 9.40 & 5.24 & 11.63 & 12.40 & 5.73 & 0.255 \\
\hline & $\mathrm{P} * *$ & & 0.638 & & & 0.107 & & \\
\hline & $\mathrm{R}$ & 10.92 & 10.25 & 4.91 & 8.89 & 9.70 & 3.40 & 0.220 \\
\hline \multirow[t]{3}{*}{ C4 } & L & 10.35 & 10.35 & 5.97 & 12.46 & 12.30 & 6.07 & 0.191 \\
\hline & $\mathrm{P} * *$ & & 0.639 & & & 0.012 & & \\
\hline & $\mathrm{R}$ & 11.57 & 10.65 & 4.36 & 9.75 & 9.80 & 2.95 & 0.177 \\
\hline \multirow[t]{3}{*}{ C5 } & L & 11.27 & 10.25 & 6.75 & 13.47 & 11.40 & 7.35 & 0.280 \\
\hline & $\mathrm{P} * *$ & & 0.974 & & & 0.021 & & \\
\hline & $\mathrm{R}$ & 13.42 & 14.00 & 4.37 & 10.46 & 11.60 & 3.89 & 0.017 \\
\hline \multirow[t]{2}{*}{ C6 } & $\mathrm{L}$ & 11.29 & 11.00 & 6.57 & 13.66 & 14.80 & 7.17 & 0.155 \\
\hline & $\mathrm{P} * *$ & & 0.131 & & & 0.022 & & \\
\hline
\end{tabular}


Table 3: Sagittal and transverse dimensions of the transverse foramina

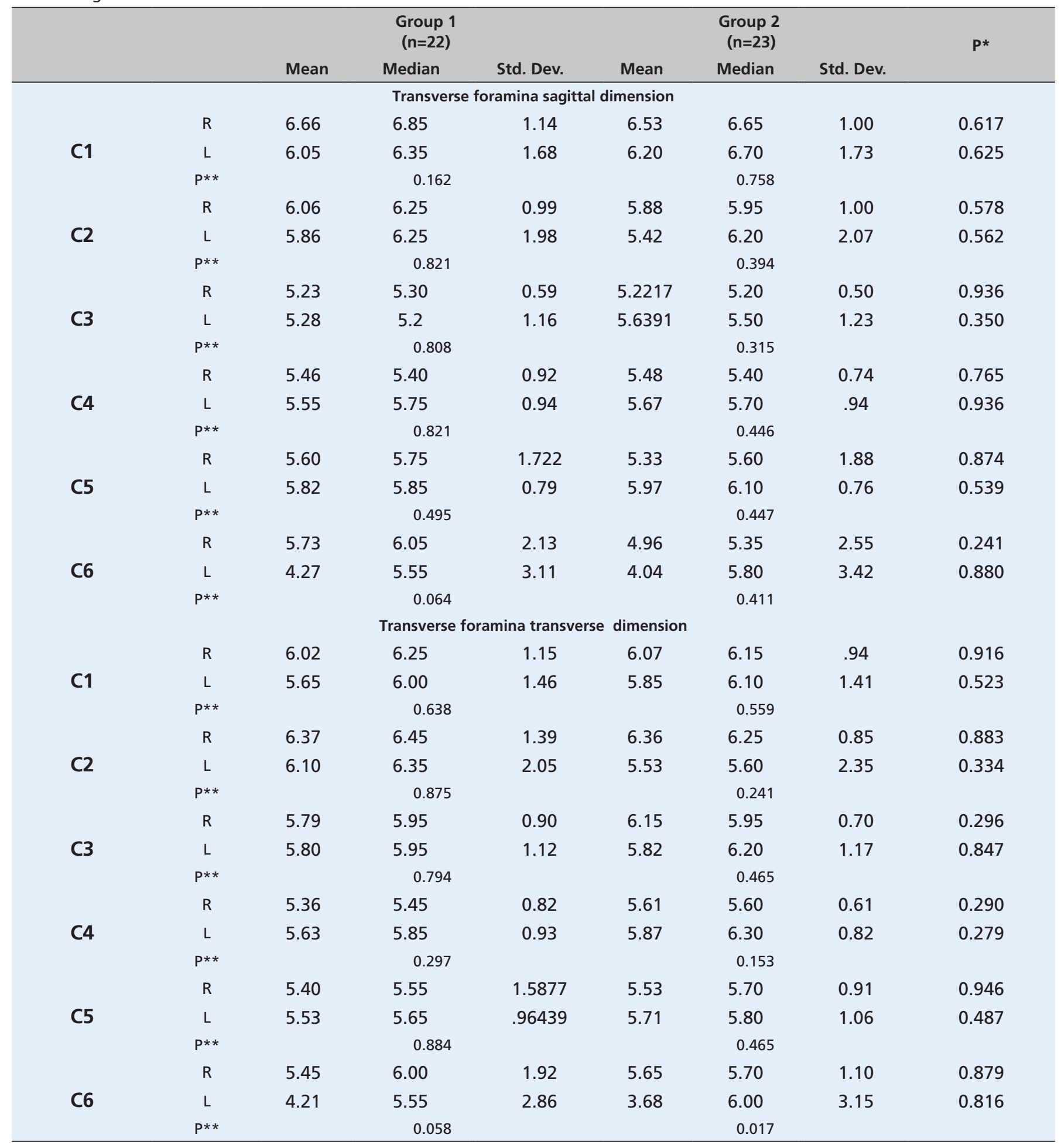

${ }^{*} p$ value shown for the results of Mann Whitney $U$ test

$* * p$ value shown for the results of Wilcoxon signed ranks test 
Kültür T et al.

Table 4: Area of the transverse foramina

\begin{tabular}{|c|c|c|c|c|c|c|c|c|}
\hline & & \multicolumn{3}{|c|}{$\begin{array}{c}\text { Group } 1 \\
(n=22)\end{array}$} & \multicolumn{3}{|c|}{$\begin{array}{c}\text { Group } 2 \\
(n=23)\end{array}$} & \multirow[b]{2}{*}{$\mathbf{P}$} \\
\hline & & Mean & Median & $\begin{array}{l}\text { Std. } \\
\text { Dev. }\end{array}$ & Mean & Median & Std. Dev. & \\
\hline \multirow{3}{*}{ C1 } & $\mathrm{R}$ & 34.96 & 33.60 & 10.89 & 26.18 & 25.32 & 9.99 & 0.007 \\
\hline & L & 30.37 & 33.05 & 10.85 & 31.91 & 33.20 & 9.92 & 0.658 \\
\hline & $P * *$ & \multicolumn{3}{|c|}{0.086} & \multicolumn{3}{|c|}{0.046} & \\
\hline \multirow{3}{*}{ C2 } & $\mathrm{R}$ & 30.69 & 31.05 & 9.02 & 31.12 & 31.80 & 6.97 & 0.803 \\
\hline & L & 31.57 & 31.60 & 14.82 & 28.28 & 27.30 & 14.61 & 0.369 \\
\hline & $\mathrm{P} * *$ & \multicolumn{3}{|c|}{0.685} & \multicolumn{3}{|c|}{0.308} & \\
\hline \multirow{3}{*}{ C3 } & $\mathrm{R}$ & 23.79 & 24.45 & 4.54 & 23.95 & 24.30 & 3.09 & 0.964 \\
\hline & L & 25.39 & 25.05 & 8.01 & 26.73 & 24.60 & 8.69 & 0.776 \\
\hline & $\mathrm{P} * *$ & \multicolumn{3}{|c|}{0.256} & \multicolumn{3}{|c|}{0.194} & \\
\hline \multirow{3}{*}{ C4 } & $R$ & 24.35 & 24.55 & 7.35 & 24.57 & 24.15 & 5.10 & 0.919 \\
\hline & L & 24.86 & 24.10 & 6.23 & 25.77 & 26.60 & 6.33 & 0.570 \\
\hline & $\mathrm{P} * *$ & \multicolumn{3}{|c|}{0.821} & \multicolumn{3}{|c|}{0.503} & \\
\hline \multirow{3}{*}{ C5 } & $R$ & 25.77 & 25.00 & 11.73 & 27.00 & 26.05 & 9.67 & 0.666 \\
\hline & L & 27.03 & 26.25 & 8.57 & 27.90 & 30.60 & 8.45 & 0.829 \\
\hline & $\mathrm{P} * *$ & \multicolumn{3}{|c|}{0.520} & \multicolumn{3}{|c|}{0.616} & \\
\hline \multirow{3}{*}{ C6 } & $R$ & 26.96 & 28.80 & 11.69 & 28.58 & 28.50 & 6.65 & 9.838 \\
\hline & L & 21.59 & 27.20 & 16.63 & 20.11 & 26.00 & 16.89 & 9.772 \\
\hline & $P^{* *}$ & \multicolumn{3}{|c|}{0.198} & \multicolumn{3}{|c|}{0.033} & \\
\hline
\end{tabular}

* $p$ value shown for the results of Mann Whitney $U$ test

** $p$ value shown for the results of Wilcoxon signed ranks test 
Table 5: Correlation tests between area of the vertebral artery and measurements of the transverse foramina in vertigo group*

\begin{tabular}{|c|c|c|c|c|c|c|c|c|c|c|c|c|c|}
\hline & & \multicolumn{12}{|c|}{ Transverse foramina } \\
\hline & & \multicolumn{6}{|c|}{ Right } & \multicolumn{6}{|c|}{ Left } \\
\hline & & \multicolumn{2}{|c|}{$\begin{array}{c}\text { C1- } \\
\text { Sagittal }\end{array}$} & \multicolumn{2}{|c|}{ C1-Transvers } & \multicolumn{2}{|c|}{$\begin{array}{l}\text { C1- } \\
\text { Area }\end{array}$} & \multicolumn{2}{|c|}{$\begin{array}{c}\text { C1- } \\
\text { Sagittal }\end{array}$} & \multicolumn{2}{|c|}{ C1-Transverse } & \multicolumn{2}{|c|}{$\begin{array}{l}\text { C1- } \\
\text { Area }\end{array}$} \\
\hline & & $r$ & p & $\mathbf{r}$ & p & $r$ & $p$ & $r$ & $p$ & $r$ & $\mathbf{p}$ & $r$ & p \\
\hline \multirow{4}{*}{$\begin{array}{c}\text { C1-Area of } \\
\text { vertebral } \\
\text { artery (VAA) }\end{array}$} & $\mathrm{R}$ & 0.550 & 0.008 & 0.348 & 0.113 & 0.472 & 0.026 & 0.309 & 0.161 & 0.147 & 0.514 & 0.340 & 0.122 \\
\hline & L & 0.147 & 0.514 & 0.288 & 0.193 & 0.362 & 0.098 & 0.431 & 0.045 & 715 & 0.000 & 0.695 & 0.000 \\
\hline & & \multicolumn{2}{|c|}{$\begin{array}{c}\text { C2- } \\
\text { Sagittal }\end{array}$} & \multicolumn{2}{|c|}{ C2-Transverse } & \multicolumn{2}{|c|}{$\begin{array}{l}\text { C2- } \\
\text { Area }\end{array}$} & \multicolumn{2}{|c|}{$\begin{array}{c}\text { C2- } \\
\text { Sagittal }\end{array}$} & \multicolumn{2}{|c|}{ C2-Transverse } & \multicolumn{2}{|c|}{$\begin{array}{l}\text { C2- } \\
\text { Area }\end{array}$} \\
\hline & & $r$ & $p$ & r & $p$ & $r$ & $p$ & $r$ & $p$ & $r$ & $p$ & $r$ & $p$ \\
\hline \multirow{4}{*}{$\begin{array}{l}\text { C2-Area of } \\
\text { vertebral artery } \\
\text { (VAA) }\end{array}$} & $\mathrm{R}$ & 0.449 & 0.036 & 0.267 & 0.230 & 0.404 & 0.062 & -0.458 & 0.032 & -0.092 & 0.684 & -0.424 & 0.049 \\
\hline & L & 0.141 & 0.532 & -0.029 & 0.898 & -0.020 & 0.930 & 0.510 & 0.015 & 0.317 & 0.150 & 0.443 & 0.039 \\
\hline & & \multicolumn{2}{|c|}{$\begin{array}{c}\text { C3- } \\
\text { Sagittal }\end{array}$} & \multicolumn{2}{|c|}{ C3-Transverse } & \multicolumn{2}{|c|}{$\begin{array}{l}\text { C3- } \\
\text { Area }\end{array}$} & \multicolumn{2}{|c|}{$\begin{array}{c}\text { C3- } \\
\text { Sagittal }\end{array}$} & \multicolumn{2}{|c|}{ C3-Transverse } & \multicolumn{2}{|c|}{$\begin{array}{l}\text { C3- } \\
\text { Area }\end{array}$} \\
\hline & & $r$ & $\mathrm{p}$ & $r$ & $p$ & $r$ & $\mathrm{p}$ & $r$ & $p$ & $r$ & $p$ & $r$ & $p$ \\
\hline \multirow{4}{*}{$\begin{array}{l}\text { C3-Area of } \\
\text { vertebral artery } \\
\text { (VAA }\end{array}$} & $\mathrm{R}$ & 0.542 & 0.009 & 0.359 & 0.101 & 0.562 & 0.007 & -0.080 & 0.722 & 0.068 & 0.764 & 0.033 & 0.885 \\
\hline & $\mathrm{L}$ & 0.261 & 0.240 & 0.283 & 0.202 & 0.149 & 0.509 & 0.635 & 0.002 & 0.467 & 0.028 & 0.591 & 0.004 \\
\hline & & \multicolumn{2}{|c|}{$\begin{array}{c}\text { C4- } \\
\text { Sagittal }\end{array}$} & \multicolumn{2}{|c|}{ C4-Transverse } & \multicolumn{2}{|c|}{$\begin{array}{l}\text { C4- } \\
\text { Area }\end{array}$} & \multicolumn{2}{|c|}{$\begin{array}{c}\text { C4- } \\
\text { Sagittal }\end{array}$} & \multicolumn{2}{|c|}{ C4-Transverse } & & \\
\hline & & $r$ & $p$ & $r$ & $p$ & $r$ & $p$ & $r$ & $p$ & $r$ & $p$ & $r$ & $p$ \\
\hline C4-Area of & $\mathrm{R}$ & 0.528 & 0.012 & 0.566 & 0.006 & 0.616 & 0.002 & 0.147 & 0.513 & 0.259 & 0.245 & 0.194 & 0.386 \\
\hline (VAA) & L & -0.282 & 0.203 & -0.047 & 0.837 & -0.297 & 0.179 & 0.619 & 0.002 & 0.542 & 0.009 & 0.642 & 0.001 \\
\hline & & $\begin{array}{r}C \\
\text { Sag }\end{array}$ & & C5-Tra & verse & & & & & C5-Tra & verse & & \\
\hline & & $r$ & $p$ & $r$ & $p$ & $r$ & $p$ & $r$ & $p$ & $r$ & $p$ & $r$ & $p$ \\
\hline C5-Area of & $\mathrm{R}$ & 0.520 & 0.013 & 0.233 & 0.296 & 0.605 & 0.003 & 0.176 & 0.433 & 0.014 & 0.950 & -0.104 & 0.644 \\
\hline (VAA) & L & 0.067 & 0.768 & -0.155 & 0.491 & 0.007 & 0.976 & 0.721 & 0.000 & 0.495 & 0.019 & 0.745 & 0.000 \\
\hline & & $\begin{array}{r}C \\
\text { Sag }\end{array}$ & & C6-Tra & verse & & & & & C6-Tra & verse & & \\
\hline & & $r$ & $p$ & $r$ & $\mathrm{p}$ & $r$ & $\mathrm{p}$ & $r$ & $p$ & $r$ & $p$ & $r$ & $p$ \\
\hline C6-Area of & $\mathrm{R}$ & 0.225 & 0.314 & 0.302 & 0.172 & 0.132 & 0.557 & -0.011 & 0.963 & 0.077 & 0.733 & 0.000 & 0.999 \\
\hline (VAA) & L & -0.079 & 0.728 & 0.077 & 0.734 & 0.036 & 0.875 & 0.376 & 0.085 & 0.210 & 0.348 & 0.135 & 0.549 \\
\hline
\end{tabular}

* $p$ value shown for the result of the Spearman's correlation rho efficient test 


\section{References}

1. No authors listed. Special report from the National Institute of Neurological Disorders and Stroke. Classification of cerebrovascular diseases III. Stroke1990; 21:637-76.

2. Grad A, Baloh RW. Vertigo of vascular origin: Clinical and electro-nystagmographic features in 84 cases. Arch Neurol 1989; 46:281-4.

3. Savitz SI, Caplan LR. Vertebrobasilar disease. N Engl J Med 2005; 352:2618-26.

4. Doss A, Phatouros CC. Vertebrobasilar insufficiency. Curr Treat Options Cardiovasc Med.2006; 8:111-9.

5. Lima Neto AC, Bittar R, Gattas GS, et al. Pathophysiology and Diagnosis of Vertebrobasilar Insufficiency: A Review of the Literature. Int Arch Otorhinolaryngol. 2017; 21:302-7. doi: 10.1055/s-0036-1593448. Epub 2016 Oct 26.

6. Thiel H, Wallace K, Donat J, Yong-Hing K. Effect of various head neck positions on vertebral artery blood flow. Clin Biomech. 1994;9:105-10.

7. Troost BT. Dizziness and vertigo in vertebrobasilar disease. Part 1: peripheral and systemic causes dizziness. Stroke 1980;11:301-3.

8. Bergan JJ, Levy JS, Trippel OH, Jurayj M. Vascular implications of vertigo. Arch Otolaryngol 1967;85:292- 7.

9. Fisher CM. Vertigo in cerebrovascular disease. Arch Otolaryngol 1967;85:529-34.

10. Haldeman S, Kohlbeck FJ, McGregor M. Unpredictability of cerebrovascular ischemia associated with cervical spine manipulation therapy: a review of sixtyfour cases after cervical spine manipulation. Spine 2002;27:49-55.

11. Gomez CR, Cruz-Flores S, Malkoff MD, Sauer CM, Burch CM . Isolated vertigo as a manifestation of vertebrobasilar ischemia. Neurology. 1996;47:94-7.

12. Grad A, Baloh RW.Vertigo of vascular origin. Clinical and electronystagmographic features in 84 cases. Arch Neurol. 1989;46:281-4.

13. Asavasopon S, Jankoski J, Godges JJ. Clinical diagnosis of vertebrobasilar insufficiency: resident's case problem. J Orthop Sports PhysTher. 2005;35:645-50.

14. Troost BT. Dizziness and vertigo in vertebrobasilar disease. Part II. Central causes and vertebrobasilar disease. Stroke 1980;11:413-5.

15. Rother J, Wentz KU, Rautenberg W, Schwartz A, Hennerici M. Magnetic resonance angiography in vertebrobasilarischemia. Stroke 1993; 24:1310-5.
16. Fox MW, Piepgras DG, Bartleson JD. Anterolateral decompression of the atlantoaxial vertebral artery for symptomaticpositional occlusion of the vertebral artery. Case report. J Neurosurg. 1995;83:737-40.

17. Vates GE, Wang KC, Bonovich D, Dowd CF, Lawton MT. Bow hunter stroke caused by cervical disc herniation. Case report. J Neurosurg. 2002;96(1 Suppl):90-3.

18. Albuquerque FC, Hu YC, Dashti SR, et al. Craniocervical arterial dissections as sequelae of chiropractic manipulation: patternsof injury and management. J Neurosurg. 2011;115:1197-205.

19. Alnaami I, Siddiqui M, Saqqur M. The diagnosis of vertebrobasilar insufficiency using transcranial Doppler ultrasound. Case Rep Med. 2012:894913. doi: 10.1155/2012/894913. Epub 2012 Nov 8.

20. Otto V, Fischer B, Schwarz M, Baumann W, Preibisch-Effenberger R. Treatment of vertebrobasilar insufficiency--associated vertigo with a fixedcombination of cinnarizine and dimenhydrinate. Int Tinnitus J. 2008; 14:57-67.

21. Ha W, Yang D, Gu S, et al.Anatomical study of suboccipital vertebral arteries and surrounding bony structures using virtualreality technology. Med SciMonit. 2014;20:802-6. doi: 10.12659/MSM.890840.

22. Cote P, Kreitz BG, Cassidy JD, Thiel H. The validity of the extension-rotation test as a clinical screening procedure before neck manipulation: a secondary analysis. J Manipulative PhysiolTher. 1996;19:159-64.

23. Westaway MD, Stratford P, Symons B. False-negative extension/rotation pre-manipulative screening test on a patient with an atretic and hypoplastic vertebral artery. Man Ther. 2003;8:120-7.

24. Rivett DA, Milburn PD, Chapple C. Negative premanipulative vertebral artery testing despite complete occlusion: a case of false negativity. Man Ther. 1998;2:102-7.

25. Jost GF, Dailey AT. Bow Hunter's syndrome revisited: 2 new cases and literature review of 124 cases. Neurosurg Focus 2015;38:E7

26. Akar ZC, Dujovny M, Slavin KV, Gomez-Tortosa E, Ausman JI. Microsurgical anatomy of the intracranial part of the vertebral artery. Neurol Res. 1994;16:171-80.

27. Gordhan A, Lockhart C. Congenital Bilateral C2 Transverse Foramina Stenosis Causing Adult-Onset Vertebrobasilar Insufficiency and Posterior Circulation Stroke. Case Rep Neurol. 2017;9:137-42.

This is an open access article distributed under the terms of the Creative Commons Attribution-NonCommercial-NoDerivs 3.0 Unported (CC BY- NC-ND3.0) Licence (http://creativecommons.org/licenses/by-nc-nd/3.0/) which permits unrestricted noncommercial use, distribution, and reproduc- tion in any medium, provided the original work is properly cited.

Please cite this article as: Kültür T, Bayar Muluk N, Iyem C, Inal M, Burulday V, Alpua M, Çelebi U. O., Anatomical Considerations: The Relationship Between The Vertebral Artery And Transverse Foramina At Cervical Vertebrae 1 To 6 In Patients With Vertigo. ENT Updates 2018;8(3): 185-194. 